\title{
Violence and Healing: Exploring the Power of Collective Occupations
}

\author{
M.R. Motimele ${ }^{1, *}$ and E.L. Ramugondo ${ }^{2}$ \\ ${ }^{1}$ Department of Health and Rehabilitation Sciences, Division of Occupational Therapy, University of Cape \\ Town, E-floor (48 Room 16), Old Main Building, Groote Schuur Hospital, RSA, South Africa \\ ${ }^{2}$ Department of Health and Rehabilitation Sciences, Division of Occupational Therapy, University of Cape \\ Town, F45, Old Main Building, Groote Schuur Hospital, RSA, South Africa
}

\begin{abstract}
The effects of violence on the person are extensive, more so, for persons disabled through violence. Research in occupational therapy has shown the effectiveness of occupations in helping displaced refugees to construct new identities and navigate new ways of belonging within asylum countries. No research thus far has focussed on the role of occupation for healing in contexts of sustained violence. Aim: To explore the role of occupations in the healing journeys of people physically impaired by violence. Study Design: Qualitative; Narrative Inquiry. Methodology: Photovoice and Narrative Interviews. Data Analysis: Narrative-analytic methods were used to produce explanatory stories. Findings: These are presented with a specific focus on the impact/influence of violence on personal and societal occupational engagement and the restorative role of collective occupations within the participants' healing journeys. The findings suggest a need to reframe violence as a collective occupation that dehumanizes, and healing as a collective process that (re)humanizes within a broader framework of Ubuntu as an interactive ethic. These findings call for a shift in focus for rehabilitation practices involving individuals disabled through violence, in contexts of sustained direct and structural violence such as South Africa.
\end{abstract}

Keywords: Violence, context, disability, healing, occupation.

\section{INTRODUCTION}

Rehabilitation therapists frequently come into contact with clients who have acquired impairments through violent incidents, particularly within the South African context (Seedat et al. 2009). There is, however, a lack of literature exploring the everyday lived experiences of this client group. Of specific interest to occupational therapists is the promotion of health and well-being through occupation-based and client-centred practice (WFOT, 2012). The current lack of literature raises questions regarding the relevance and suitability of existing occupational therapy services in violent contexts such as South Africa, for this client group. This is particularly so, if occupational therapists have not grappled with what it means to have acquired an impairment through violence and explored the process of healing thereafter. The impact of context on this experience of disability and the process of healing, especially given that these clients often continue to reside in areas where they acquired impairments through violent acts from others, also requires exploration. Focussing on the occupational engagements of these clients in isolation, without regard to personal narratives and contextual factors that impact on these stories, goes against clientcentred practice.

*Address correspondence to this author at the F45 Old Main Building, Groote Schuur Hospital, Observatory 7925, South Africa; Tel: +27 (0) 21406 7704; Fax: +27 (0) 21406 6323; E-mail: maps.motimele@gmail.com
Through gaining a deeper understanding of the participants' experiences, this study aimed to explore the potential role of occupation(s) in the healing journey for people who had been impaired/disabled through violence. This article will briefly review relevant literature exploring the nature and consequences of violence in a South African context; the limited, often fractured understanding of the person's journey of healing and the role of occupation(s) within this process.

Thereafter, the study methodology, data collection methods and key excerpts and photographs from participant stories will be shared. The article concludes with a discussion of the findings presented in relation to emerging theory on collective human engagements, or occupations.

\section{REVIEW OF LITERATURE}

The literature review will begin by exploring the culture, character and consequences of violence in the South African context. Thereafter 'healing' as a potential response to violence will be explored, highlighting the difficulties of finding a universal definition of the term and the limited understanding of this process in literature. Lastly, the historical role and use of occupations in mediating adverse circumstances faced by refugees in terms of sustained trauma from countries of origin and challenges in constructing new lives in foreign countries will be explored. This 
Table 1: Violent Crime Statistics, South Africa 2011/2012 ${ }^{\mathrm{a}}$

\begin{tabular}{|c|c|c|c|c|}
\hline $\begin{array}{c}\text { Category of violent } \\
\text { crime }\end{array}$ & $\begin{array}{c}\text { Numbers reported } \\
\mathbf{( 2 0 1 1 / 2 0 1 2 )}\end{array}$ & $\begin{array}{c}\text { Incidents committed by a } \\
\text { spouse/partner/family } \\
\text { member/friend } \\
\text { (\%) }\end{array}$ & $\begin{array}{c}\text { Incidents committed by } \\
\text { known perpetrator (\%) }\end{array}$ & $\begin{array}{c}\text { Incidents committed } \\
\text { by unknown } \\
\text { perpetrator (\%) }\end{array}$ \\
\hline \hline Assault & 381180 & 20.9 & 29.9 & 10.5 \\
\hline Sexual assault & 64514 & 35.7 & 38.4 & 18.6 \\
\hline Murder & 15609 & 30.3 & 47.2 & 7.8 \\
\hline Public violence & 1152 & - & - & - \\
\hline
\end{tabular}

a Information compiled from; Statistics South Africa- Victims of Crime Survey 2010/2011: 3 and South African Police Service Website, 2013.

exploration highlights the potential value in taking an occupational perspective on healing in the context of sustained violence, as is the situation in South Africa, particularly for individuals who are physically impaired as a consequence of violence. The section will conclude with the relatively new shift in focus in occupational therapy literature from individual to collective occupations.

\section{South Africa: A Violent Context}

South Africa has become infamous for the high levels of violent crime. Phrases such as 'a culture of violence' and 'rape capital of the world' show the globally accepted view of South Africa as a violent context (Hamber and Lewis, 1997; Jewkes and Abrahams, 2002: 1232). These statements imply that violence is not an external phenomenon that occurs or happens to the person and/or communities, but rather a modus operandi that South Africans have adopted as a means of negotiating relationships with each other, within context.

Violence is defined by The World Health Organization (WHO) as 'the intentional use of physical force or power, threatened or actual, against oneself, another person, or against a group or community, that either results in or has a high likelihood of resulting in injury, death, psychological harm, mal-development or deprivation' (Krug et al. 2002: 5). Violent contexts are environments that have high incidents of violent crime, war-torn areas and situations of conflict.

The above table and statistics bring to light interesting dynamics about the nature of violent crime in South Africa namely; perpetrators of violent crime are likely known to their victim(s), the incidence of violence between the perpetrator and victim of violence is highest in familial or intimate relationships; implying that the potential for a person to become a victim of violent crime is highest within their own home. These dynamics call for a deeper understanding of violence and violent crime in South Africa.

\section{Understanding South Africa's 'Culture of Violence'}

There are many factors that contribute to the high incidence of violence in South Africa. These include poverty, unemployment, a history of Apartheid, access to firearms, patriarchal notions of masculinity, substance abuse and income inequality (Seedat et al. 2009). South Africa's history of Apartheid highlights a specific period where violence was used by the government in power to enforce this oppressive doctrine through the assault of detainees, torture of suspected 'terrorists', and the killing of political rivals (Hamber, 1999). Those opposing the Apartheid regime did so through acts of sabotage, neck-lacing ${ }^{1}$ of suspected informants, and military training of the resistance movements such as Umkhonto We Sizwe ${ }^{2}$ (Hamber 1999, Motumi, 1994).

Ho (2007: 1) in her essay exploring structural violence as a human rights violation argues that the 'unequal share of power to decide over the distribution of resources' was a key factor responsible for the perpetuation of structural inequalities resulting in constrained agency. Structural violence is understood as: the avoidable disparity between the potential ability to fulfil basic needs and their actual fulfilment, resulting in disparities of power (Ho, 2007). With this lens, South Africa's Post-Apartheid context, in which the historical unequal distribution of power has resulted in presentday power and structural inequalities, is understood as a violent context. Violence is/was used as a means to enforce power or respond to being disempowered,

${ }^{1}$ Neck-lacing is a form of 'political punishment' adopted in South Africa during the Apartheid regime. The act involves placing a tyre soaked in petrol around the victim's neck and setting it alight (Ball, 1994).

${ }^{2}$ Umkhonto we Sizwe was the military wing of the African National Congress (ANC) during the Apartheid era (Ngculu, 2003). 
showing how South African identities and interactions are/were shaped through interaction within context. The fact that violence was and remains expressed in South Africa as a response to an oppressive government, although true, is only partially true. Violence is also perpetuated by citizens on one another through violent crime, and aggressive forms of interaction and communication within households and communities (Hamber, 1999). Hamber (1999:123) gives an apt description of the problem by recognizing that 'the socially sanctioned use of violence to solve problems has saturated South African life'. Numerous incidents of expressions or 'ruptures' of anger, frustration, shame and a loss of respect continue to be visible manifestations of the insidious culture of violence (Keet, 2009).

\section{The 'Character' of Violence}

Acts of violence include murder, rape, assault, intimidation, torture and abuse (Statistics South Africa, 2012). Violence involves both perpetrators and victims of violence and any citizen has the potential to fall into either one or both of these categories. In addition, incidents of violence can, and often do include the broader community. Examples of this include domestic violence and vigilantism. Both of these forms of violence require implicit approval or desensitization from the wider social context in order to be practiced as widely as they are (Thaler 2012, Knox et al. 2011).

Although occurring as physical, sexual, emotional and financial abuse within family homes, domestic violence has the potential to negatively affect all levels of society (van der Hoven, 2001). The most tragic consequence being unsafe homes where children adopt the violent tendencies they are exposed to as a norm, thereby perpetuating the use of violence as a response to problems and as a means of gaining and/or maintaining control within families and broader social contexts (van der Hoven, 2001). Women specifically are often victims of gender-based and intimate partner violence. Intimate-partner violence involves; 'the control, intimidation and subjugation of one's intimate partner' (Ansara, 2009: 188). These forms of violence are all indicative of the dominant patriarchal system within the South African society, and consequently women and children especially, face the greatest risk of violence within their homes.

Vigilante violence is problematic for several reasons; the most significant being that vigilante groups are unregulated. An unregulated body such as this has the potential to create a breeding ground for the perpetration of human right violations, with most acts of injustice going unreported (Hamber 1999; Harris, 2000). Furthermore, the existence of such groups indicates a distrust or lack of faith in the existing protective services such as the police force and the judicial system. Police officers themselves, often having a history of using violence to intimidate, obtain information and exert power. This implies that as a country, South Africans often do not view the use of violence as wrong or detrimental, but rather, as an effective means of seeking justice.

Vigilante violence can be viewed as and is a form of collective violence (Duncan, 2005). Collective violence is described by WHO (2002: 1) as; 'the instrumental use of violence by people who identify themselves as members of a group - whether this group is transitory or has a more permanent identity - against another group or set of individuals, in order to achieve political, economic or social objectives.' Using this definition as a lens, we see vigilante violence as a single representative of a broader collective violence used as common means and practice by members of the public and at times, employees of the state.

\section{Consequences of Violence}

Black (2011: 219), an occupational therapist who worked with Guatemalan refugees in North America who had been victims of torture in their country of origin, describes the negative effects of violence on a population as fuelling 'a cycle of intimidation, and alienation, ultimately corrupting human connections and creating isolation'. Furthermore, torture disrupts families, creates fearful and distrustful communities, and limits people's feelings of power to influence change, highlighting the impact of violence on the person within context (Black, 2011). In her work with the refugees, Black found that the most detrimental and damaging effects of this type of violence on the individual's spirit lay in the objectification of the tortured person; into an 'object to despise' (Black, 2011: 219). Special attention needs to be drawn to the use of the word 'object' as it encapsulates the dehumanisation experienced by victims of violence.

One such example of the dehumanisation of victims of violence is the Xenophobic attacks that occurred in South Africa in 2008. Xenophobia, defined as 'negative attitude' or 'feeling of hatred' directed towards foreign nationals manifests in 'practices that result in bodily 
harm and damage' (Harris, 2002: 170). Mostly perpetuated by black South Africans on other black African nationals, the reasons cited for xenophobia have been broadly attributed to competition for limited resources between the two groups (Tshitereke, 1999). The dehumanisation of the 'other' in this period resulted in the burning of shops and small businesses owned by black foreign nationals who often lived in the informal settlements together with black South Africans. Other violent acts included brutal assault and murder (Harris, 2002). Perhaps the most profound tragedy of this and other such cases, is that the victim's identity is viewed with hatred, directly opposing the African spirit of Ubuntu described by van Marle and Cornell (2005: 205) as 'an interactive ethic, or an ontic orientation in which who and how we can be as human beings is always being shaped in our interaction with each other'. Incorporating the Ubuntu perspective, it is evident how violent interactions systematically sever the ties that connect people to each other. Points of relation or commonality are destroyed, and the 'other' is seen as an enemy or entity that needs to be eradicated.

Violence is the second leading cause of death and disability in South Africa, second only to HIV/AIDS (Seedat et al. 2009; Mathers, Boerma and Fat, 2009). Violence creates high mortality and disability rates, both of which are preventable. Less visible after-effects on the person include emotional numbing, hyper vigilance and distrust (McLeod, 2009). These consequences have been likened to those experienced by torture survivors and need to be understood within the social, cultural and spiritual context of individuals affected (Quiroga and Jaranson, 2005). The consequences of violence that are of specific interest to this study given an occupational therapy perspective are those of impairment and disability.

Both the social and the medical models of disability were applicable in this study, in that disability as a phenomenon arises from social stigma and the disabling political, social and economic environment, as well as a result of the individual's acquired impairment(s) (Phillips, 2005). Using both the medical and social model of disability, the person's subjective experience is important, but the context cannot be ignored. This is particularly critical because most people, who have acquired an impairment through violence, are likely to continue living in such violent contexts (Seedat, 2009).
Treloar (2002: 597) in a study exploring the experiences of adults with disabilities and their family members found that participants experienced physical, emotional and spiritual trials and difficulties related to their acquired disability status. These trials and difficulties centred on loss of identity and function, and feelings of being punished by God. Literature on the experiences of people disabled through violence is scarce; further confirming the wide-spread 'normalisation' of violence and secondly, supporting the need for further research in this area.

\section{Healing}

To find a universal definition of healing in literature proved difficult. This is because healing has predominantly been used in the medical field, based on the medical model and has referred primarily to the 'physiological processes related to curing' (Egnew, 2005: 255). Furthermore, the processes involved in healing have not been adequately explored in health related literature. Beyond the health sciences, different aspects of healing are acknowledged by different disciplines. Healing in medicine is often different to the understanding of the term in psychology and sociology. Healing in the latter two disciplines identifies relevant aspects linked to 'social organization, roles, meaning, and personal growth' (Egnew, 2005).

Further compounding the challenge of clearly defining the term 'healing' is the often interchangeable use of the word with other words that do not fully represent its holistic meaning. These are recovery, rehabilitation and cure, highlighting a culture of correction and cure and omitting a fundamental element; care (Egnew, 2005). In addition 'healing' has been associated and is often confused with 'the alternative', 'the esoteric' or 'the spiritual' (Egnew, 2005; Hsu et al. 2008).

In a study by Hsu et al. (2008), researchers investigated the views of patients and clinicians on the central concept of healing. Focus groups were facilitated with health professionals and patients separately and then together. Results showed that definitions held by physicians and other health professionals lacked empathy, communication and acknowledgment of the health professionals' relationships with patients. These elements were identified as central to healing by patients. Acknowledgment of the health professional's relationship with the patients' alludes to the social 
context playing a key role in one's experience of healing.

Interestingly, when the focus groups were mixed (patients and health care providers) the following definition emerged; healing is 'the process of moving toward balance and well-being that implies making changes and the blending of the physical, mental and spiritual' as well as 'the restoration of health with caring acceptance and understanding' (Hsu et al. 2008: 309). The second definition implies that healing is not a process that can be achieved in isolation, but depends heavily on the support available to the injured/unhealthy or disabled person. In addition, the fact that this definition came about after talks and discussions between health care providers and consumers of health services indicates that a universal definition and understanding of healing can emerge through dialogue, communication and collaboration between sectors, professionals and patients.

Themes that were drawn from the above study shed light on the nature or stages of healing, they were: healing is multi-dimensional and holistic; healing is a process and a journey; the goal of healing is recovery or restoration; healing requires the person to reach a place of personal balance and acceptance and lastly; relationships are central to healing (Hsu et al. 2008). These themes highlight the multi-faceted and social nature of the term 'healing'; aspects of which are not always considered when using the term.

A holistic definition of healing from the nursing literature is provided by Dossey et al. (2005: 48), who defines healing as; 'the emergent process of the whole system bringing together aspects of one's self and the body, mind, emotions, spirit and environment, at deeper levels of inner knowing, leading toward integration and balance with each aspect having equal importance and value'. This definition is holistic as it not only takes into account the physical, mental and spiritual nature of healing but also implies aspects of subjective meaning and personal understanding within context (Egnew, 2005). Attention to context in exploring healing suggests that it is no longer understood as purely an individualistic phenomenon, but perhaps also partly a collective process.

\section{The Use of Occupation to Promote a New Identity and a Sense of Belonging}

In occupational therapy literature, occupation is broadly understood to refer to the "chunks of culturally and personally meaningful activity in which humans engage in that can be named in the lexicon of culture' (Clarke et al. 1991: 301). This definition, although encompassing of the many aspects that contribute to one's experience of occupation, does not sufficiently emphasize the often inextricable interaction between person and context.

In order to emphasize the transactional relationship between person and context, thereby highlighting the individual's relationship to and impact on the context and vice versa, Cutchin et al. propose that occupation can be understood as: 'a type of relational action through which habit, context, and creativity are coordinated toward a provisional yet particular meaningful outcome that is always in process' (Cutchin et al. 2008: 164). This definition of occupation proposes a transactional relationship between person and context, Although this definition is useful in understanding the individual within context, our 'interconnectedness' as humans remains unacknowledged and the process of meaning-making within context is thus not fully reflected.

Ramugondo and Kronenberg (2013) further propose an understanding of human occupation that emphasises interconnectedness and seeks to dissolve the dichotomy between individualistic and collective notions of this construct. Collective occupations are thus defined as: 'Occupations that are engaged in by individuals, groups, communities and/or societies in everyday contexts; these may reflect an intention towards social cohesion or dysfunction, and/or advancement of or aversion to a common good' (Ramugondo \& Kronenberg 2013: 17). This definition is of interest to this study for two reasons. Firstly, violence can be understood and therefore further investigated as a collective occupation, providing more insight into this practice within a South African context as in the example of vigilante violence discussed earlier. Using a collective occupation lens, incidents of vigilante violence can be understood through the added and arguably fundamental angle of intent.

Secondly, in alluding to social cohesion and a common good, this construct may bear synergies with collective aspects to healing as a process that extends beyond the individual. The scope of this study is thus expanded, allowing for the exploration of occupations that individuals, physically impaired through violence, engage in as part of a group and/or a broader community, and not only those that they partake in 
alone. This view of occupation aligns with Black's work with disabled Bosnian women (Black, 2011).

In her description of collaborative community-based occupational therapy involving displaced Bosnian women, Black (2011) highlights how engagement in meaningful occupations can influence social change. She describes how these women, through making and selling their hand-crafted wares to their newly-found community, experienced the achievement of dual goals. Firstly, through participation in the occupation of craft-making and being part of the group they were learning to cope with feelings of anxiety, depression and isolation associated with their refugee status, and secondly, their occupational engagement (with others) created opportunities for their culture, identity and contributions to be recognized in their unfamiliar contexts, fostering a new sense of belonging.

This example indicates the need to connect with others and to re-establish one's identity are important for the person's healing journey. Violence may precipitate and perpetuate occupational apartheid (Kronenberg et al. 2005) because it compromises the search for meaning and exploration of understanding of the self and others and the world that occurs through acting in and on the world.

\section{METHODOLOGY}

This study was qualitative in nature, following Narrative Inquiry as the experience of those who had acquired a physical impairment through violence was the phenomenon under study.

\section{Sampling}

Potential participants were identified during practice as an occupational therapy clinical educator and by colleagues who had been informed about the research study. Reasons for targeting a total number of six participants is that this number was small enough to allow for in-depth knowledge of persons' experiences but also large enough to include representatives from all contexts in the Western Cape, according to the demographics shown in the table. Although the researcher managed to secure only four participants, the findings obtained are still relevant in that the stories generated provide an in-depth account of the participants' experience within context.

\section{Ethics}

Ethical guidelines were considered before the study commenced, during the research process, and after the data was collected. Guidelines ensured the address of any potential vulnerability that partaking in the study might have created (Liamputtong, 2007). Approval for this study was granted by the University of Cape Town's Human Research Committee [HREC REF: 529/2011].

\section{DATA COLLECTION}

Photo voice and Narrative Interviews were used as data collection tools. Participants were asked to capture themselves engaging in everyday occupations using a photographic medium. Photographs can be seen as a form of story-telling and are particularly effective as a resource for narrative inquiry (Harrison, 2002). The Narrative Interview is a form of unstructured, in-depth interview with specific features. It 'envisages a setting which encourages and stimulates interviewees to tell a story about some significant event in the informant's life' (Bauer, 1996:2). The idea is to reconstruct social events from the perspective of informants as authentically as possible. Participants were encouraged to share their experiences prompted by the broad question: 'What happened to you?' Participant photographs were used during the interviews to elicit influencing contextual information and provide a description of occupational engagement and assigned meaning.

\section{ANALYSIS}

Data was analysed using Narrative Analysis, thereby producing an 'emplotted narrative'. The role of

Table 2: Final Participant Sample

\begin{tabular}{|c|c|c|c|}
\hline $\begin{array}{c}\text { Participant: } \\
\text { (Self-chosen pseudonym) }\end{array}$ & Race & Gender & Socio-Economic Status \\
\hline \hline Al Capone & Black & Male & low \\
\hline Papa & Black & Male & low \\
\hline Smiggs & Coloured & Male & low \\
\hline Lucky & Coloured & Female & \\
\hline
\end{tabular}


researcher entailed the uncovering of a plot from participants' accounts that linked the events shared by participants in their interviews, thereby giving the events meaning in attainment of a purpose or goal. Polkinghorne (1995:15) suggests that researchers identify 'a bounded system of study', to ensure that the data collected relates to the experience under investigation. The bounded system, and experience under investigation relevant to this study, was the healing journey(s) of the individual(s) who acquired a physical impairment/disability through violence.

\section{FINDINGS}

In this article participant narratives will not be presented as a whole; rather aspects of the narrative for each participant will be shared. Participant pictures that show and/or imply new insights gained regarding healing, violence and the potential power of collective engagement in occupations will also be presented, as relevant.

\section{Al Capone's Story}

Al Capone lives in an area of Cape Town called Gugulethu. This is a place in the Western Cape with the highest prevalence of trauma due to violent acts. In 2012, Gugulethu reported 1146 violent crimes; 120 murders, 106 attempted murders, 257 sexual assaults and 663 incidents of assault with intent to inflict grievous bodily harm. Al Capone was shot and became paralysed as a result of a stray-bullet.

"I was very hurt. Even today l'm still hurt because the thing that happened in the township. You were once a person... You were once a person who could walk (mumbles). No hey it's painful.'

After the injury, Al Capone isolated himself from the public and the community. He also withdrew from his family within the household. He would stay in his room alone, watching television all day. During this time he was pre-occupied with thoughts about where his life was headed and sadness that it would never be the same again. He did not want to be seen in public as he feared he would be ridiculed or ostracized because he was in a wheelchair. The combination of depression, isolation and community attitudes towards disability meant that Al Capone stopped socializing with his friends and eventually lost contact with them.

\section{Smiggs's Story}

Smiggs is a thirty year old coloured male living in Elsiesrivier, an area that was set aside for people falling under the 'coloured' race category during the apartheid regime. Although this doctrine is no longer law in South Africa, many people are still in the areas assigned to them under the Group Areas Act, 1995. Elsiesrivier is riddled with socio-economic problems that include high rates of crime, gangsterism and drug abuse.

At the time of the shooting that would leave Smiggs disabled, he was a member of a well-known gang, notorious for acts of violence, turf-wars, dealing with illegal firearms as well as drug and substance abuse. Shooting at 'targets,' and being a target himself, were part and parcel of gang life. Smiggs spent sporadic periods in prison from the age of 14 . Prison in this context is known for extreme instances of violence amongst inmates that result in either disability or death.

Outside of prison, life was just as violent, turf wars and planned assassinations of rival gang-members were daily incidents that Smiggs and his fellow gangmembers planned and executed. Smiggs displayed leadership skills within the gang; he was an effective member and was therefore well respected. As his family ties and relationships suffered due to his drug abuse and gang-related activities, he began to identify fully with his position in the gang and the gangsters' way of life.

“We are gangsters, we are evil, we don't worry about what we do, do you understand? And the story travelled, my name stuck, its Heinie, you understand, you see?"

Smiggs' turning point came when he was spending his last term in prison; at this point he had acquired the impairment. For the first time he started thinking about what would happen to him if his mother died and could no longer look after him. With the support of a respected community member recruited by his family to counsel him, Smiggs realised that he needed to accept his disability status and return to work if he was to have a healthy and safe life. Smiggs shares that he will never fully accept his disability, but he knew he had to accept it to some extent if he was going to move forward with his life. 
When discussing the anticipated future in his healing journey, Smiggs shared that he would like to mend his relationship with his mother and broken relationships with his siblings. When he considers what he put them all through, he knows that it will be a difficult process. Smiggs has started sharing his story with youths who he identifies as being at risk of following the same destructive path as his. He shares that his turning point was also influenced by someone who cared enough about him to listen, talk to and counsel him. He wants to do the same.

"you just need support, you understand? Maybe that person doesn't have support at home, you understand? Maybe I can give it to him/her. "

\section{Lucky's Story}

Lucky is a 42 year old coloured woman who became paralyzed as a result of a gunshot injury that left her with a spinal cord injury. Lucky currently lives in Delft, an informal settlement 30 minutes from the Cape Town Central Business District. 'The Hague' is one of the six subdivisions of Delft and this is where Lucky lives with her husband Beetle and son Lubee. The Hague is predominantly an Afrikaans-speaking coloured area; with a small percentage of its residents black Africans. High levels of violence, substandard housing, poor infrastructure and access to amenities are starkly evident twenty years post Apartheid.

Lucky's paralysis would come about from a shooting perpetrated by one of the acquaintances that she and her husband used to smoke socially with. During the difficult time she initially had after acquiring her impairment, Lucky recalls that it was a comment from her son that made her realise that she had to make a change and start accepting her life with paraplegia;

"...because he say, 'yoh, Mammie you cannot do anything for me anymore. If there is a problem, Mammie cannot run for me anymore'. Because I used to be there for my children. But ok, as time went on, I decided, no, my husband works for me, he looks after me, I had to accept this. And I had to do it for my husband and my son. "

Lucky enjoys chatting to people and helping them cope with their problems. She feels that because of her experience she has something to contribute, and is able to refer to a very difficult time in her life to help others. She reports that the experience is cathartic for her. She also acknowledges her faith and relationship with God as a positive contributor to her healing process.

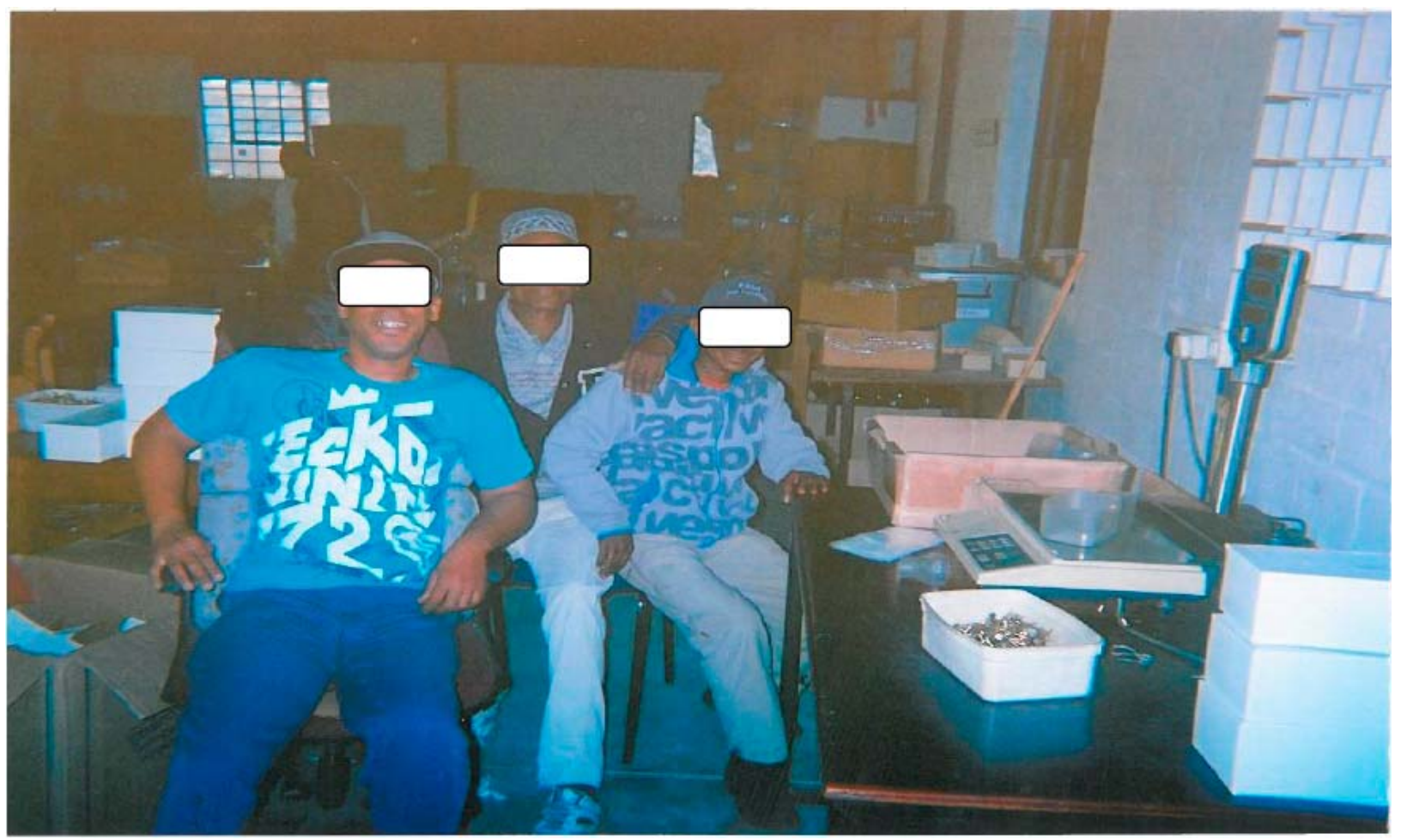

Figure 1: Smiggs (left) chatting to his friends/colleagues. 


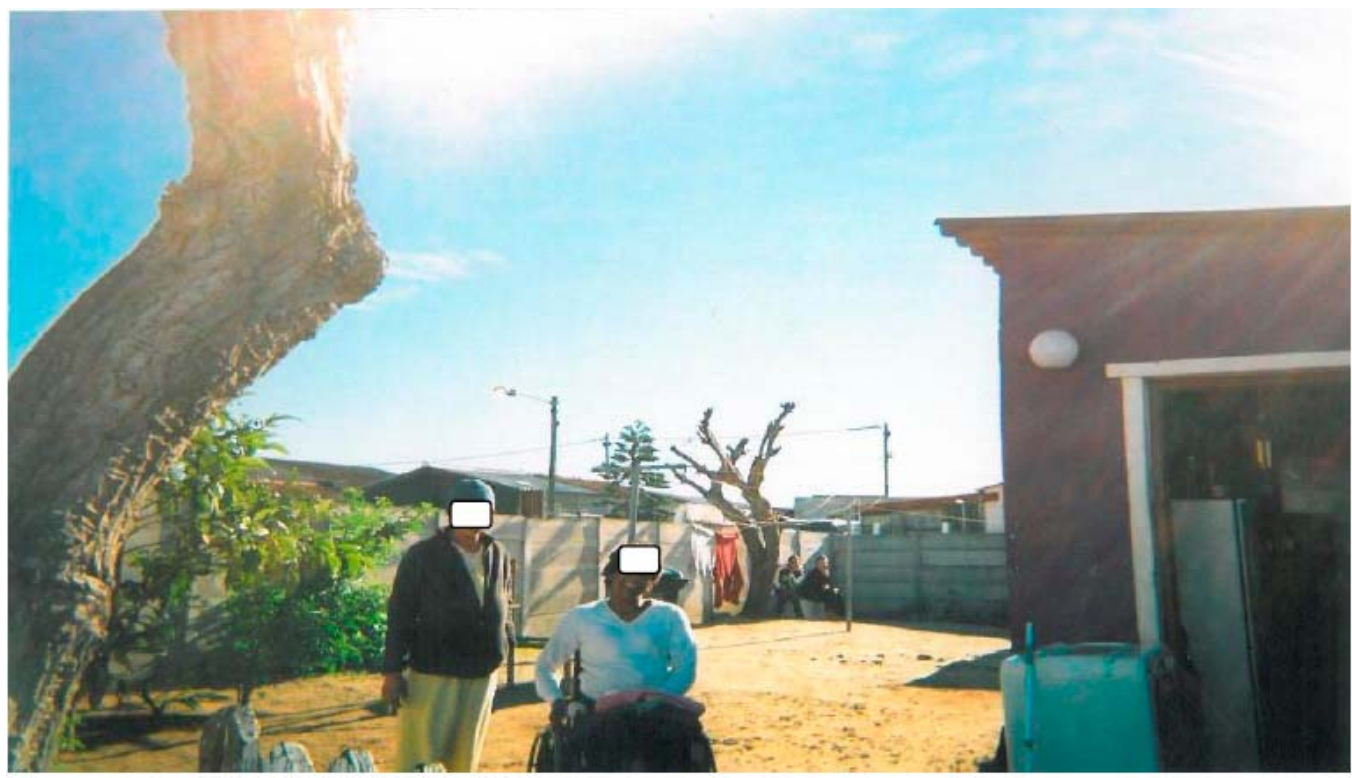

Figure 2: Lucky (right) pictured chatting to a neighbour who is experiencing a difficult time.

"Most of the people got trust in me, because here are some people like this Pastor's wife, sometimes she's depressed and then she's coming to me, but she's the Pastor's wife. I'm like a social service now. People, sometimes people come to me, they talk and you know, everybody come and talk and this is problem and that problem."

Lucky feels that she was and continues to be let down by the system. The man who shot her never served jail-time for this incident. He was arrested and sentenced to 38 years in prison for shooting and killing a tourist, an incident which occurred five days after Lucky's shooting. Lucky was advised to press charges against the state, and was assigned a lawyer. The lawyer assigned proved unreliable and neglected Lucky's case. Attempts to contact him were evaded and Lucky suspects that he may have been corrupt.

\section{Papa's Story}

Papa acquired his disability at the hands of a vigilante community group after the community identified him as a suspect in recurrent burglaries in the neighbourhood. He was taken out into the street with his hands tied behind his back and marched over to a nearby house - the house of the man in the neighbourhood known for 'discipline' - a euphemism for the use of or threat of violence to extract information from suspected criminals in the community. After being interrogated, while continuously denying the accusation, Papa remembers being struck by something metal on the head as he was speaking, and falling down to the ground. He was then taken onto the street and beaten with bricks, kicked and beaten by a group of people he could not identify.

"In the road, in the road with cars. Ei sister, I heard very softly that they were talking saying, "This person deserves bricks, bricks to beat his head into a pulp with, yes so he dies because these people came here late to cause trouble here". Ei sis I don't know what happened. They hit me, even when I was unconscious, when I was dead sister, so there was nothing to do... I was completely knocked out."

Papa spent months in a coma, and a further couple of months after that in rehabilitation to regain function. At present he is ataxic as a result of head injuries suffered during the attack. Severely depressed and isolated from community life for years after his attack, Papa's turning point came with the passing of his grandmother;

"She passed away, after her death, at home they said she is no longer around so now each person has to stand up for themselves, because there is no older woman, you have to make a plan. I was living alone and in time I concluded that I would find someone to help me like find a disability grant to support myself."

Papa also values time spent with friends and acknowledges them as a key source of support in his life. 


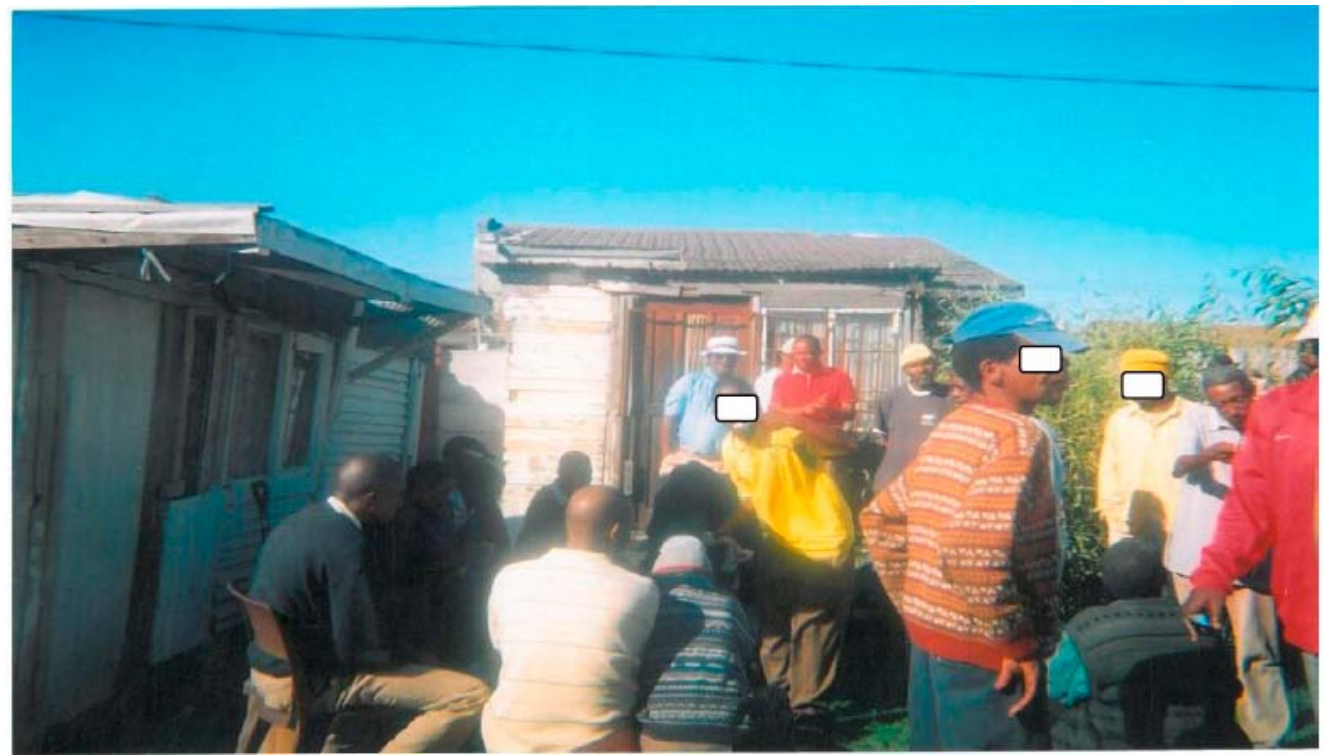

Figure 3: Papa (middle) and his friends attending a function hosted by his girlfriend's family.

\section{DISCUSSION}

Participant's stories offered interesting insights into the interface between violence, disability, and healing. Similarly, for the role of collective occupation within the healing journey for those who acquire an impairment/disability through violence. This section discusses these new insights.

Perhaps the best starting point to this discussion is to position the fairly new concept of 'collective occupation' within the scarcity of a 'collective perspective of occupation' in occupational therapy literature (Peralta-Catipon, 2012; Ramugondo \& Kronenberg, 2013). Historically, occupational science has focused on occupation from the individual's perspective. Dickie et al. (2006: 83) critique this individualism by highlighting that occupations are hardly ever 'individual in nature'. In the narrative extract from Al Capone, a seemingly individual occupation of watching television alone, in fact perpetuates feelings of social isolation. Dickie et al. (2006) propose that an interpretation of occupation from only an individual's perspective limits a comprehensive understanding of the transactional relationship between person and context. This, coupled with occupational therapy's focus on health promoting and 'positive' occupations (Law et al. 1998; Angell, 2012), further limit an understanding of the assigned meaning and purpose of collective occupational engagement.

Ramugondo \& Kronenberg's (2013: 8) definition of collective occupation responds to these limitations in that it acknowledges that these occupations may 'reflect an intention towards social cohesion or dysfunction, and/or advancement of or aversion to a common good.' The ability of collective occupations to perpetuate just and/or oppressive social practices, is further confirmed by Angell (2012), raising a fundamental question: what motivates participation in collective occupation? Ramugondo \& Kronenberg (2013) propose that an understanding of the intent informing collective occupation is necessary if we are to make sense of past and present collective occupational engagement.

\section{Violence: Collective Occupation that Dehumanizes}

Freire (1968: 28) aptly describes dehumanization as not only a tangible historic fact or a given destiny, but also as "...the result of an unjust order that engenders violence in the oppressors, which in turn dehumanizes the oppressed ". This was evident in narratives from the current study.

Participant's stories illustrate the dehumanizing nature of South Africa's culture of violence, with detrimental consequences for both the individual and the collective while the intent is often related to the exertion of power. Papa was beaten by a group of community members in response to crimes they believed him to have committed. After they had dragged him into the street he recalls them discussing the collection of; 'bricks to beat his head into a pulp with'. During the attack he lost consciousness; 'They hit me, even when I was unconscious, when I was dead sister.' 
Smiggs engaged in many collectively violent acts against others as a member of a notoriously brutal gang. In his story he shares that 'shooting at targets, and being a target himself' were part and parcel of daily life for one belonging to a gang. "We are gangsters, we are evil, we don't worry about what we do." The characterization of self and the collective as 'evil', in reference to the violent extremes they were willing to go to, and often suffered as a result of, is evident. Evil is synonymous with 'malice' and alludes to elements of wickedness, depravity and disregard for human-life.

Al Capone captures the dehumanizing nature of violence vividly in his story of his healing journey following an impairment sustained through violence; 'You were once a person... You were once a person who could walk...' From Al Capone's account, we come to understand disability, resulting from violence, as a loss of personhood.

Van Marle and Cornell (2005) offered a fresh perspective on the concept of Ubuntu, highlighting the 'interconnectedness' of human beings or interactive ethic, with both the collective and the individual sharing responsibility for the other's becoming. Violence, in direct contrast, perpetuates issues of difference, and within a structurally violent context such as South Africa, often incites further incidents of violence against the 'other'. If we consider van Marle and Cornell's (2005: 205) particular notion that 'who and how we can be as human beings is always being shaped in our interaction with each other', then we see how violent interactions within context have the ability to block any potential for expressions of freedom and agency, infringing on one's human rights at both a personal and systemic level $(\mathrm{Ho}, 2007)$.

Lucky's experience highlights the systemic nature of violence, and how individual agency and access to human rights are constrained by this. She shares in her story that she felt let down by the law, both in the police's failure to apprehend her shooter after her attack and in subsequent legal proceedings. Her limited understanding of and fair access to legal processes and procedures put her in a disadvantaged position, rendering her vulnerable to exploitation. The power granted to legal professionals by the state coupled with legal services that are often inaccessible to the poor, resulted in mismanagement and neglect of her case. The fact that her shooter was only arrested after he shot a tourist reduces her sense of value as a citizen and as a human being.
Under Apartheid law in South Africa, non-whites were victims of both structural and direct violence, suffering constant collective humiliation and limited participation in meaningful occupation. Doing with others outside of one's racial group was discouraged through criminalizing inter-racial socialization or relationships. Doing for others was perverted and exploited through discriminative laws, mass servitude and enslavement of non-whites. Although now a democratic state, incidents of violence (including structural violence) are still evident in South Africa, ensuring that 'who and how we can be' is continuously being restricted by participation in collective occupation that dehumanizes. Van Marle \& Cornell (2005) confirm the disempowering nature of violence for survivors and perpetrators, oppressor and oppressed, through the notion that discriminative practices rob both parties of their humanity.

\section{Healing: A Possibly Collective Process}

The term 'healing' has proven to have no universal definition and is subject to both the field of enquiry and the individual undergoing the process. The findings in this study show that whether one is healed or not is based on the individual's subjective understanding of the term and their personal experience of the process. Participants did not only refer to their individual physical healing, but also the process of rebuilding a (positive) sense of self and (re)building meaningful relationships. These relationships ranged from family ties and friendships to a personal connection with a higher spiritual being.

Smiggs shared two goals in his story that he would like to achieve in the anticipated future. The first, focussed on the opportunity to mend the broken relationship with his mother and the second; to identify and support at risk youth like he had once been himself. Smiggs was able to rebuild a positive sense of self through contributing to the well-being and development of others; confirming both parties' sense of value.

Lucky shares that she became a 'support service' to some of her neighbours. Chatting with fellow neighbours and giving advice based on her experiences allowed her the space to do and be with others in a way that enhanced both her and her neighbours' sense of value and belonging. Lucky's experience illustrates how the collective nature of healing promotes spaces for one to become a person through interactions with others that value each 
person's contribution to shaping other's experience of humanness. Lucky's relationship with God also played a substantial part in her process of healing. Forgiving her shooter and others she felt had wronged her, brought her a sense of peace, and re-affirmed her identity as a child of God.

The collective nature of healing is reiterated in $\mathrm{Al}$ Capone's and Papa's stories. Before the positive turning point in the healing journey, Al Capone and Papa report a withdrawal from family members, community or both. Their resultant isolation, a manifestation of their depression linked to their disability status and loss of functioning, physically separated them from others. Although providing both men with an 'escape' from the anticipated social stigma, their isolation denied both individuals and the broader context the opportunity to (re)shape each other. The potential to highlight new capabilities and to foster positive social transformation is thus denied. This matches with Van Marle \& Cornell's (2005) view of the person and the community as always in a process of becoming. When there is stigma about disability, and isolation of the individual as a response, both the individual and the broader community/society are denied expression and/or experience of their humanity.

\section{Healing: A Process of Becoming Human Again?}

Building on earlier discussion points regarding the dehumanizing nature of violence and the collective nature of healing, the proposal that healing may be a process of 'becoming human again' is supported.

The first leg of this argument is centred on new insights gained regarding 'healing'. When revisiting Al Capone's experience of disability as a result of violence where he shares that; "You were once a person... You were once a person who could walk", we see that his sense of humanity was related to his ability to walk and function. Considering the permanence of his paralysis, as is the case for Smiggs, Lucky and Papa, and the fact that all these individuals consider themselves to be healed to some extent, it emerges that healing cannot only be viewed as a return of the individual to their previous physical state. This is a view supported by literature (Egnew, 2005) as well as the WHO's (2002) definition of health as 'a state of complete physical, mental and social well-being and not merely the absence of disease or infirmity.' What is further highlighted in the current study is the collective process of healing that promotes a positive sense of self and encourages one to (re)build meaningful relationships.
The second leg of this argument is based on Van Marle and Cornell's (2005) offerings regarding the philosophy of 'Ubuntu', more specifically the notion that one's experience of humanness is constantly being shaped through connections and interactions with others. Van Marle and Cornell (2005:206) also dismiss the often held notion about Ubuntu as communalism or communitarianism; a privileging of community over the individual. They argue instead that it is about a process where both the community and the individual come to be. With regards to the individual, they stress the point about how he or she "is given the chance to become a person at all". The community in turn, is judged in accordance with how it empowers individuals, in other words, how those who make up the community, regardless of capacity or any other means of differentiation, are able to feel as human beings. Participant stories showed how a sense of belonging and healing arose from being with others, and being afforded opportunities to rebuild a positive identity and meaningful relationships. Smiggs highlights a turning point in his healing journey, being an instance when someone cared enough about him to listen. Being affirmed as a human being by another sparked a life trajectory for Smiggs, to want to do the same for others, in complete contrast to how he viewed himself and life during his involvement in gangsterism.

When examining both legs in relation to each other we understand healing to be a process of regaining ones humanity, a process that cannot be achieved outside of the connections and relationships with others, within context.

\section{CONCLUSION}

The need for rehabilitation therapists to understand the experience of healing for those who have acquired impairment through violence in contexts of sustained direct and structural violence is important if therapists are to develop appropriate services for this client group. This article provided a conceptual foundation to exploring the nature and consequences of violence in a South African context; addressing the limited, often fractured understanding of the disabled person's journey of healing and the role of occupation(s) within this process.

Through the exploration of narratives involving four South Africans disabled through violence, the study illustrated how the dehumanizing nature of South Africa's culture of violence, results in detrimental consequences for both the individual and the collective, 
and often masks unequal power relations that continually constrain individual agency and access to human rights, sustaining a suspended state of continuous dehumanization. Acquired physical impairment or disability, in interaction with social stigma within this violent context, is experienced as loss to personhood, with the resultant withdrawal from community further perpetuating a sense of isolation.

Interestingly, the healing journeys emerging from the narratives point less to individual restoration of physical capacity or function, and more to the process of rebuilding a (positive) sense of self and (re)building meaningful relationships. Collective occupation as a concept that invokes intent with regards to what individuals do in order to build or negate social cohesion is thus affirmed, suggesting its potential to furthering our understanding on how on the one hand, violence is a collective act that dehumanizes, and on the other healing is a process that involves creating spaces for humanizing interactions with others. Similarly, van Marle and Cornell's (2005) fresh perspective on Ubuntu as an interactive ethic, highlighting the responsibility shared by both the collective and the individual in shaping the other's becoming, is advanced. Framing participant narratives within the relatively new concept in occupational therapy, collective occupation, and the well-known African ethic of Ubuntu, this paper proposes a new understanding of healing in the context of continuous dehumanization through direct and structural violence, as a process of feeling human again.

\section{REFERENCES}

Angell, Amber Michelle. 2012. "Occupation-Centered Analysis of Social Difference: Contributions to a Socially Responsive Occupational Science." Journal of Occupational Science 21(2): 1-13.

Ansara, Donna and Hindin, Michelle. 2009. "Perpetration of Intimate Partner Aggression by Men and Women in the Philippines: Prevalence and Associated Factors." Journal of Interpersonal Violence. 24(9): 1579-1590.

http://dx.doi.org/10.1177/0886260508323660

Ball, Joanna. 1994. "The Ritual of the Necklace." Research report written for the Centre for the Study of Violence and Reconciliation. Retrieved 27 March 2013 (http://www.csvr. org.za/index.php?option=com_content\&view=article\&id $=1632$ \%3Athe-ritual-of-the-necklace\& Itemid=29)

Bauer, Martin. 1996. "The Narrative Interview: Comments on a Technique of Qualitative Data collection" in Papers in Social Research Methods-Qualitative Series, Vol. 1. London: London School of Economics, Methodology Institute.

Black, Mary. 2011. "From Kites to Kitchens: Collaborative Community-Based Occupational Therapy with refugee Survivors of Torture." Pp. 217-226 In Occupational Therapy without Boarders Vol 2: Towards an ecology of occupationbased practices edited by F. Kronenberg, N. Pollard, D. Sakellariou. Oxford: Elsevier-Churchill Livingstone.
Clark, Florence. Diane Parham, Mike Carlson, Frank Gayla, Jeanne Jackson, Doris Pierce, Robert Wolfe, Ruth Zemke. 1991. "Occupational Science: Academic Innovation in the Service of Occupational Therapy's Future. The American Journal of Occupational Therapy. 45(4): 300-10. http://dx.doi.org/10.1177/0886260508323660

Cutchin, Malcom. Rebecca Aldrich, Antoine Luc Baillard and Susan Coppola. 2008. "Action Theories for Occupational Science: the Contributions of Dewey and Bourdieu." Journal of Occupational Science. 15 (3): 157-164. http://dx.doi.org/10.1080/14427591.2008.9686625

Dickie, Virginia., Malcom Cutchin and Ruth Humphry. 2006. "Occupation as Transactional Experience: A Critique of Individualism in Occupational Science." Journal of Occupational Science. 13(1): 83-93. http://dx.doi.org/10.1080/14427591.2006.9686573

Dossey, Barbara M, Lynn Keegan, Cathie E Guzzetta. 2005. Holistic Nursing: A Handbook for Practice. Vol 4. Sudbury: Jones \& Bartlett Publishers.

Egnew, Thomas R. 2005. "The Meaning of Healing: Transcending Suffering." The Journal of Family Medicine 3: 255-262.

Freire, Paulo. 1968. Pedagogy of the Oppressed: Chapter 1. New York: Seabury.

Hamber, Brandon and Sharon Lewis. 1997. "An Overview of the Consequences of Violence and Trauma in South Africa." Research report written for the Centre for the Study of Violence and Reconciliation. Retrieved 27 March 2013 (http://www.csvr.org.za/index.php?option=com_content\&view $=$ article\&id=1778\%3Aan-overview-of-the-consequences-ofviolence-and-trauma-in-south-africa\&ltemid=31 [2013, 27 March)

Hamber, Brandon. 1999. "Have no doubt it is fear in the land". Journal of Political Psychology. 7: 113-128.

Harris, Bronwyn. 2002. "Xenophobia: A New Pathology for a New South Africa." Pp. 169-184 in Psychopathology and Social Prejudice edited by D Hook and G Eagle. Cape Town: University of Cape Town Press.

Harrison, Barbara. 2002. "Photographic visions and Narrative Inquiry." Journal of Narrative Inquiry 12(1): 87-111. http://dx.doi.org/10.1075/ni.12.1.14har

Ho, Kathleen. 2007. "Structural Violence as a Human Rights Violation." The Essex Human Rights Review Journal 4(2): 117.

Hsu, Clarissa. William R Phillips, Karen J. Sherman, Rene Hawkes, Daniel C Cherkin. 2008. "Healing in Primary Care: A Vision shared by Patients, Physicians, Nurses and Clinical staff." The Journal of Family Medicine. 6(4): 307-312.

Jewkes, Rachel and Naeema Abrahams. 2002. "The Epidemiology of Rape and Sexual Coercion in South Africa: an Overview". The Journal of Social Science \& Medicine. 55 (7): 12311244.

http://dx.doi.org/10.1016/S0277-9536(01)00242-8

Keet, Andre. 2009. "Mutual Vulnerability: a Key Principle in a Humanising Pedagogy in Post-conflict Societies." Perspectives in Education. 27(2): 109-119.

Knox, Michelle S, Kimberley Burkhart, Kimberley E Hunter. 2011. "ACT Against Violence Parents Raising Safe Kids Program: The Effects on Maltreatment-Related Parenting Behaviours and Beliefs." Journal of Family Issues 32(1): 55-74. http://dx.doi.org/10.1177/0192513X10370112

Kronenberg, Frank and Nick Pollard. 2005. "Overcoming Occupational Apartheid." Pp 58-86 in Occupational Therapy without Borders: Learning from the spirit of survivors Vol 1. edited by F. Kronenberg and N. Pollard. Amsterdam: Elsevier Publishers.

Krug, Ettiene G., James A Mercy, Linda L Dahlberg and Anthony B Zwi. 2002. "The World Report on Violence and Health." The Journal of Public Health 360: 1083-88. 
Law, Mary., Sandy Leclair and Leanne Steinwender. 1999. "Occupation, Health and Well-being." The Canadian Journal of Occupational therapy 65(2): 81-91. http://dx.doi.org/10.1177/000841749806500204

Liamputtong, Pranee. 2007. Researching the Vulnerable: a Guide to Sensitive Research Methods. London: Sage.

Mathers, Collin D., Ties Boerma and Doris Ma Fat. 2009. "Global and Regional causes of Death." The British Medical Bulletin 92: 7-32. http://dx.doi.org/10.1093/bmb/ldp028

McLeod, John. 2009. "The Counsellor's Workbook: Developing a Personal Approach." United Kingdom: Open University Press.

Motumi, Tsepe. 2004. "Self-Defense Units: A Brief Examination of their History and a Look at their Future." African Defense Review 15: 7-9.

Ngculu, James .2003. "The Role of uMkhonto we Sizwe in the Creation of a Democratic Civil-Military Relations Tradition." Pp 22-23 in Ourselves to Know edited by R Williams, G Cawthra and D Abrahams. Pretoria: Institute for Security Studies.

Peralta-Catipon, Terry. 2012. "Collective Occupations Among Filipina Migrant Workers: Bridging Disrupted Identities." Occupation, Participation and Health 32(2): 14-21. http://dx.doi.org/10.3928/15394492-20110805-01

Phillips, Sarah D. 2005. Disability and Citizenship in Post-Soviet Ukraine: An Anthropological Critique. Bloomington: Indiana University Press.

Polkinghorne, Donald E. 1995. "Narrative Configuration in Qualitative Analysis." Journal of Qualitative studies in Education 8(1): 523. http://dx.doi.org/10.1080/0951839950080103

Quiroga, Jose and James Jaranson. 2005. "Politically Motivated Torture and it's Survivors: a Desk Study Review of the Literature." Torture Journal on Rehabilitation of Torture Victims and Prevention of Torture 15: 2-3.

Ramugondo, Elelwani and Frank Kronenberg .2013. "Explaining Occupations from a Human Relations Perspective. Bridging the Individual-Collective Dichotomy." The Journal of Occupational Science. Advance online publication. http://dx.doi.org/10.1080/14427591.2013.781920

Seedat, Mohammed., Ashley Van Niekerk, Rachel Jewkes, Shenaaz Suffia and Kopano Ratele. 2009. "Violence and Injuries in South Africa: Prioritising an Agenda for Prevention." The Lancet Journal 374: 1011-22. http://dx.doi.org/10.1016/S0140-6736(09)60948-X
South African Police Service Website, 2013. Retrieved 27 March 2013 (http://saps.gov.za/resource centre/publications/ statistics/crimestats/2011-2/crime_stats.php[2013, 27 March)

Statistics South Africa. 2012. Victims of Crime Survey 2012. Retrieved 27 March 2013 (http://www.statssa.gov.za/ publications/P0341/P03412012.pdf)

Thaler, Kai.2012. "Norms about Intimate Partner Violence: A Quantitative and Qualitative Vignette Analysis." CSSR Working Paper 302. Pp 1-33. Retrieved 27 March 2013 (http://www.cssr.uct.ac.za/sites/cssr.uct.ac.za/files/pubs/WP3 02_0.pdf)

Thibeault, Rachael. 2011. "Rebuilding Lives and Societies through Occupation in Post-Conflict Areas and Highly Marginalized Settings." Pp 155-162 In Occupational Therapy without Boarders Vol 2: Towards an ecology of occupation-based practices edited by F. Kronenberg, N. Pollard, D. Sakellariou. Oxford: Elsevier-Churchill Livingstone.

Treloar, Linda L. 2002. "Disability, Spiritual Beliefs and the Church: the Experiences of Adults with Disabilities and Family Members." Journal of Advanced Nursing 40(5): 594-603. http://dx.doi.org/10.1046/j.1365-2648.2002.02417.x

Tshitereke, Clarence. 1999. "Xenophobia and relative deprivation." Crossings 3(2): 4-5.

van der Hoven, Anna. 2001. "Domestic Violence in South Africa." Acta Criminologica 14 (3): 13-25.

van Marle, Karin and Drucilla Cornell. 2005. "Exploring Ubuntu: Tentative Reflections." African Human Rights Law Journal 5(2): 195-220.

Whiteford, Gail E. 2005. "Understanding the Occupational Deprivation of Refugees: A case-study from Kosovo." Canadian Journal of Occupational Therapy 72: 78-88. http://dx.doi.org/10.1177/000841740507200202

World Federation for Occupational Therapists Website. 2012. Retrieved 30 June 2013 (http://www.wfot.org/aboutus/aboutoccupationaltherapy/definitionofoccupationaltherapy.aspx)

World Health Organisation Website. 2001. "Health Topics: Disabilities." (http://www.who.int/topics/disabilities/en/)

World Health Organisation Website. 2002. "World Report on Violence and Health." Retrieved August 2014 (http://www.who.int/ violence_injury_prevention/violence/world_report/en/full_en. pdf)

\section{DOI: http://dx.doi.org/10.6000/1929-4409.2014.03.33}

(C) 2014 Motimele and Ramugondo; Licensee Lifescience Global.

This is an open access article licensed under the terms of the Creative Commons Attribution Non-Commercial License (http://creativecommons.org/licenses/by-nc/3.0/) which permits unrestricted, non-commercial use, distribution and reproduction in any medium, provided the work is properly cited. 